\title{
Assesment of Gross Motor Skills as a Part of Child's Physical Readiness for Compulsory School Attenadance
}

\author{
Zdeněk Rechtik \\ Correspondence: Zdeněk Rechtik, Lecturer, Palacky University in Olomouc, Faculty of Education, Department of \\ Primary and Pre-primary education, Czech.
}

Received: July 27, 2018 Accepted: October 24, $2018 \quad$ Online Published: November 29, 2018

doi:10.11114/jets.v6i11a.3809

URL: https://doi.org/10.11114/jets.v6i11a.3809

\begin{abstract}
Children in the Czech Republic before the beginning of compulsory school attendance undergo assessment evaluating so called school readiness. The part of this evaluation is assessment of children's biological, mental, social and emotional readiness for the demands of school education. The assessment of gross motor skills is an important part of this evaluation. But motor skills are also connected not only with academic achievement but also with physical activity in future lifestyle. Therefore is the aim of the research analysis of gross motor skills in pre-school children. The research group consisted of 232 children (102 boys, 130 girls) from kindergartens and nursery schools at the age 5,9 1,63 years. For the assessment of gross motor skills was used TGMD-2 test battery. The results show strong relationship between locomotor and manipulative skills in children at pre-school age. The results indicate strong positive correlation $r=0,76$ on the significance level $p<0,05$ between locomotor and manipulative skills. From the results is obvious that teachers in kindergartens should focus on the development of locomotor skills, which are strongly connected with manipulative skills. That means pre-school teachers should focus on basic skills and then develop them which could result in highly motor-skilled children with interest in physical games and activities. The data was obtained within the project GF_PdF_006_2018. According to preference of parents' sedentary lifestyle the physical activity of Czech children at younger school age is lowering. Possibilities for improvement we see in the aimed development of gross motor skills in Czech kindergartens and nursery schools.
\end{abstract}

Keywords: gross motor skills, children

\section{Intorduction}

The issue of school maturity and school readiness is one of the essential components of the work of teachers and pedagogues. Not only in the Czech Republic, children from nursery schools at different ages before entering school are assessed whether they are mature enough and ready for school entrance and compulsory school attendance (Roebers, Röthlisberger, Neuenschwander, Cimeli, Michel, Jäger, 2014). One part of the assessment is evaluation of children's biological, mental, social and emotional readiness for the demands of school education. One of the most important elements in this assessment is the assessment of the level of gross motor skills. Because for children with movement impairments (5-10\% of children have a diagnosis of a disorder of coordination), the school environment can be very challenging (Pagani \& Messier, 2012). Nowadays, a number of studies have been published, dealing with the relationship among gross motor skills, fine motor skills, graphomotorics, visual-motorics and cognitive components (Stöckel \& Hughes, 2016; Donnelly, Hillman, Castelli, Etnier, Lee, Tomporowski, Lambourne, Szabo-Reed, 2016; Cameron, Cottone, Murrah, Grissmer, 2016; Hillman \& Biggan, 2017). Therefore, it is important to focus on the development of motor skills already in pre-school children. That is why the aim of this study is to assess the level of gross motor skills in pre-school Czech children in selected regions. This issue may also be a subject of lifelong education for pre-school teachers and pre-school staff who can increase the level of gross motor skills due to regular intervention (Ericsson, M. K. \& Karlsson, 2014). These people can build the foundations for young children to devote themselves to some type of physical activity throughout their lives, which again has many proven benefits (Temple, Crane, Brown, Williams, Bell, 2016; D’Hondt, Deforche, Gentier, Verstuyf, Vaeyens, Bourdeaudhuij, Philippaerts, Lenoir, 2014).

In current and long-term studies, gross and fine motor skills vary in predictive validity. Gross motor skills are key and at the same time a critical part of children's evolving social competencies and physical health (Sattelmair, \& Ratey, 2009; Wilson, Piek, \& Kane, 2013). Children who are clumsy, cumbersome or not so skilled in movements can be socially refused or lacking self-confidence to participate in games or sports (Skinner, \& Piek, 2001). For four to six year 
old children with low motor skills, internalising symptoms, such as anxiety, may be due to poor social skills (Wilson, Piek, \& Kane, 2013). There are very few cross-cultural tools for assessing early child development. Yet assessment of core cognitive and motor skills in the early years is important for evaluating health and educational interventions (Pitchford \& Outhwaite, 2016). Physical education may help to improve the physical activity level and has an important role in the development of fundamental movement skills (Sgró, Schembri, Nicolosi, Manzo, Lipoma, 2013). All those researches are reasons for better understandment of the role of motor skills in pre-school education. Of all the above-mentioned studies, it is clear how important role in the life of a preschool children plays physical activity, and is subsequently reflected in school achievements and adaptation to compulsory school attendance. It is precisely for all these reasons that the aim of this study is to analyze the level of motor skills in pre-school children in selected regions of the Czech Republic.

\section{The aim of the research}

The aim of the research is analysis of gross motor skills in pre-school children in chosen regions of the Czech Republic. Partial aim of the research is comparison of motor skills between genders.

\section{Methods}

\section{Research group}

The research group consisted of 232 children (102 boys, 130 girls) from kindergartens and nursery schools at the age $5,9 \pm 1,63$ years. Height and weight were normal according to WHO child-growth standards. No child was handicapped. The project was realized from March to May 2017 on pre-primary schools in the Czech Republic. The research was approved by Ethical Committee of author's authorities. Legal representatives (children's parents) were informed about aims, methods and process of research before the start of the research. Also, the anonymity of obtained data was declared. All questions about research were answered by researchers. After that legal representatives confirmed the agreement about the participation of their children in the research. Obtained data were processed anonymously. Possible questions from children were answered adequately to their age. The participation in the research was voluntary, without reward and no benefits for participants. The pupils could interrupt or leave their participation during the research anytime. Data were obtained within the project GF_PdF_2018_006.

\section{Research methods and techniques}

The level of gross motor skills was monitored by Test of Gross Motor Development-2 (Ulrich, 2000). The test consists of two subtests: locomotor skills and manipulative skills. Obtained standard scores are converted on percentile and motor quotient [Gross motor quotient (GMQ)]. Based on GMQ, the level of motor skills is assessed in the following categories: very superior (>130 points), superior (121-130 points), above average (111-120 points), average (90-110 points), below average ( $80-89$ points), poor ( $70-79$ points) and very poor ( $<70$ points).

\section{Statistical Processing}

Basic statistic values about research group (number of girls and boys, average, height, weight and age of probands) are expressed by average number and standard derivation number. Standard score and GMQ was assessed based on current methodology (Ulrich, 2000). The relationship between the level of locomotor and manipulative skills was found by Spearman correlation coefficient. The level of significant importance was declared on $p<0.05$. Data were processed by software STATISTICA, version 13.0 (StatSoft).

\section{Findings}

The results show strong relationship between locomotor and manipulative skills in children at pre-school age. The results indicate strong positive correlation $r=0,76$ on the significance level $p<0,05$ between locomotor and manipulative skills.

The positive thing is that in the area of gross motor skills most of the pre-school children achieved average or higher gross motor level (73\%). In the average category was found 35\% of pre-school children and above average $15 \%$. Category superior scored $13 \%$ of children and $10 \%$ of most skilled pre-school children were in very superior category. Low number of probands was in poor $(8 \%)$ and very poor category $(5 \%)$. In the below average category was found $14 \%$ of children. In the subtest of locomotor skills, the probands scored in average 34,03 $\pm 10,03$ points, while in the subtest skills of the manipulative skills the average score was 30,60 \pm 9,41 points. The average GMQ achieved by the research group was $103,94 \pm 21,92$. 


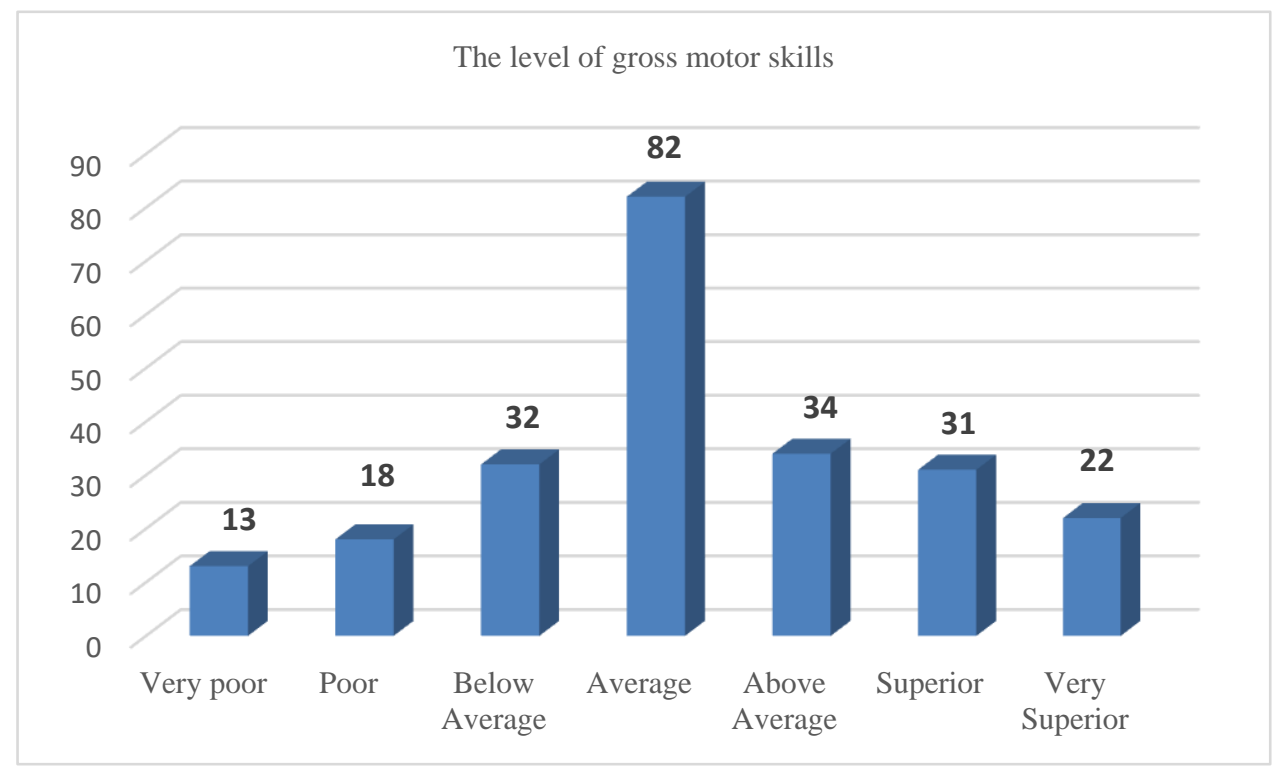

Graph 1. Categories according to the GMQ level of boys and girls $(n=232)$

Legende1. GMQ-Gross Motor Quotient; number of probands-the occurrence frequency of people in the categories of the Gross Motor Quotient

Further was the partial aim of the research to compare gross motor skills in terms of gender. From the results is clear that girls better in locomotor skills than boys but the difference is not significant (Graph 2). Girls scored in average $34,57 \pm 10,38$ points from maximum of 48 points. On the other hands boys scored 33,33 $\pm 9,57$. But boys scored more points in manipulative part of the motor skills test. They achieved 30,89 $\pm 9,83$ points while girls scored 30,37 $\pm 9,10$. From the result we can see that the differences according to gender are not significant at this age. So the children are primarily on the same staring point.

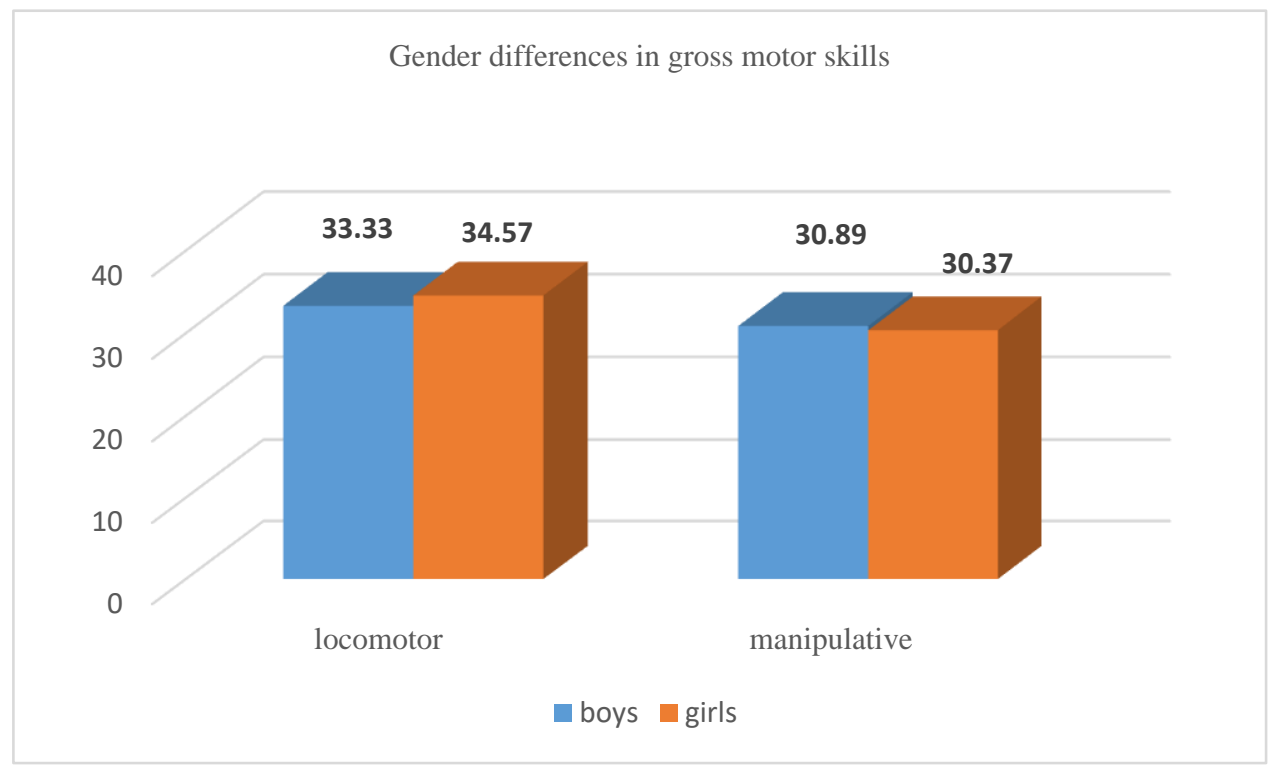

Graph 2. Gender differences between boys and girls in locomotor and manipulative skills $(n=232)$

Legende: Gender differences in gross motor skills; number of points in locomotor and manipulative skills categories

\section{Results, Conclusions and Recommendations}

The research results indicate strong positive correlation $r=0,76$ on the significance level $p<0,05$ between locomotor and manipulative skills in 232 pre-school children from chosen region of Czech republic. There was also found difference between genders, when girls are better in locomotor skills than boys but the difference is not significant. That 
is in accordance with the research from Australia (Hardy, King, Farrell, Macniven \& Howlett, 2010). From the results is clear that by supporting the role of preschool education in the process of lifelong learning in the field of physical education and by searching for possibilities of aimed interventions for motor development we can gradually achieve a higher level of motor skills, which are connected to academic achievement, healthy lifestyle and so on (Demih \& Landi, 2010; Houwen, Visser, van der Putten \& Vlaskamp, 2016). Therefore, aimed support for the lifelong learning of a wide range of motor skills from childhood as a prerequisite for a positive approach to physical activity is highly important (Barnett, van Beurden, Morgan, Brooks \& Beard, 2010; Wrotniak, Epstein, Dorn, Jones \& Kondili, 2006; Lubans, Morgan, Cliff, Barnett, L. M. \& Okely, 2010; Spessato, Gabbard, Valentini \& Rudisill, 2013). Motor deficiencies in the area of motor skills highlight the possibility of learning disabilities. This is confirmed by numerous researches (Haapala, 2013; Lopes, Santos, Pereira \& Lopes, 2013; Pitchford, Papini, Outhwaite \& Gulliford, 2016; Goodway, Robinson \& Crowe, 2010; Westendorp, Hartman, Houwen, Smith \& Visscher, 2011).

Despite the relatively positive results of research, with 73\% (169 out of 232) children achieving the average and higher level of motor skills, it is very important for pre-school teachers to focus on the development of basic motor skills, whether gross or fine. As a pyramid, we can imagine the amount of learned motor skills, so we have to build solid foundations in pre-school age so that we can develop the learned basic skills in the next development of the individual. Furthermore, it is clear from the results that in terms of gender, differences in locomotor and object control skills are not yet significant. Because as many studies suggest, gender differences occur primarily at later age (Goodway, Robinson \& Crowe, 2010; Lin \& Yang, 2015; Barnett, van Beurden, Morgan, Brooks \& Beard, 2010). In the Czech Republic there are not many trainings for pre-school teachers focused on the development of motor skills. In our opinion this could be changed thanks to development of more workshops and training programs aimed on the development of basic skills in pre-school age should. The way for improvement of the level of motor skills of children could be intervention programs, which we know rather from foreign research (Castetbon \& Andreyeva, 2012; Geertsen, Thomas, Larsen et al., 2016; Bellows, Davies, Anderson \& Kennedy, 2012; Jones, Riethmuller, Hesketh, Trezıse, Batterham, Okely, 2011) than from our environment. There is a lot of ideas for targeted development of motor skills in children, and it is now up to the state and educational institutions to offer accessible opportunities for lifelong education of teachers and pedagogical staff, which would lead to an increase in children's motor skills. Because motor skills have many benefits from which children can benefit in later life, either at school or in a future job.

\section{References}

Barnett, L. M., van Beurden, E., Morgan, P. J., Brooks, L. O., \& Beard, J. R. (2010). Gender Differences in Motor Skill Proficiency From Childhood to Adolescence, Research Quarterly for Exercise and Sport, 81(2), 162-170. https://doi.org/10.1080/02701367.2010.10599663

Bellows, L. L., Davies, P. L., Anderson, J., \& Kennedy, C. (2012). Effectiveness of a Physical Activity Intervention for Head Start Preschoolers: A Randomized Intervention Study. American Journal of Occupational Therapy, 67(1), 28-36. https://doi.org/10.5014/ajot.2013.005777

Cameron, C. E., Cottone, E. A., Murrah, W. M., \& Grissmer, D. W. (2016). How Are Motor Skills Linked to Children's School Performance and Academic Achievement? Child Development Perspectives, 10(2), 93-98. https://doi.org/10.1111/cdep.12168

Castetbon, K., \& Andreyeva, T. (2012). Obesity and motor skills among 4 to 6-year-old children in the united states: nationally-representative $\quad$ surveys. BMC $\quad$ Pediatrics, 12(1). $\quad$ ISSN $\quad$ 1471-2431. https://doi.org/10.1186/1471-2431-12-28

D’Hondt, E., Deforche, B., Gentier, I., Verstuyf, J., Vaeyens, R., De Bourdeaudhuij, I., ... Lenoir, M. A (2014). Longitudinal Study of Gross Motor Coordination and Weight Status in Children. Obesity, 22, 1505-1511. https://doi.org/10.1002/oby.20723

Demih, A. M., \& Landi, A. K. (2010). Comparison of the basic motor abilities and school achievements in the first grade elementary school boys who attended preschool with those who did not. Br J Sports M, 44(Suppl I), 1-82. https://doi.org/10.1136/bjsm.2010.078725.181

Donnelly, J. E., Hillman, C. H., Castelli, D., Etnier, J. L., Lee, S., Tomporowski, P., ... Szabo-Reed, A. N. (2016). Physical Activity, Fitness, Cognitive Function, and Academic Achievement in Children: A Systematic Review. Med Sci Sports Exerc, 48(6), 1197-1222. https://doi.org/10.1249/MSS.0000000000000901

Ericsson, M. K., \& Karlsson. (2014). Motor skills and school performance in children with daily physical education in school-a 9-year intervention study. Scand J Med Sci Sports, 24, 273-278. https://doi.org/10.1111/j.1600-0838.2012.01458.x

Geertsen, S. S., Thomas, R., Larsen, M. N. et al. (2016). Motor Skills and Exercise Capacity Are Associated with 
Objective Measures of Cognitive Functions and Academic Performance in Preadolescent Children. PLOS ONE, 11(8), e0161960. ISSN 1932-6203. https://doi.org/10.1371/journal.pone.0161960

Goodway, J. D., Robinson, L.,E., \& Crowe, H. (2010). Gender Differences in Fundamental Motor Skill Development in Disadvantaged Preschoolers From Two Geographical Regions, Research Quarterly for Exercise and Sport, 81(1), 17-24. https://doi.org/10.1080/02701367.2010.10599624

Haapala, E. A. (2013). Cardiorespiratory Fitness and Motor Skills in Relation to Cognition and Academic Performance in Children - A Review. Journal of Human Kinetics, 36(1), 55-68. ISSN 1899-7562. https://doi.org/10.2478/hukin-2013-0006

Hardy, L. L., King, L., Farrell, L., Macniven, R., \& Howlett, S. (2010). Fundamental movement skills among Australian preschool children. Journal of Science and Medicine in Sport, 13(5), 503-508. https://doi.org/10.1016/j.jsams.2009.05.010

Hillman, C. H., \& Biggan J. R. (2017). A Review of Childhood Physical Activity, Brain, and Cognition: Perspectives on the Future. Pediatric Exercise Science, 29, 170-176. https://doi.org/10.1123/pes.2016-0125

Houwen, S., Visser, L., van der Putten, A., \& Vlaskamp, C. (2016). The interrelationships between motor, cognitive, and language development in children with and without intellectual and developmental disabilities. Research in Developmental Disabilities, 19-31. https://doi.org/10.1016/j.ridd.2016.01.012

Jones, R. A., Riethmuller, A., Hesketh, K., Trezıse, J., Batterham, M., \& Okely, A. D. (2011). Promoting fundamental movement skill development and physical activity in early childhood settings: a cluster randomized controlled trial. Pediatric Exercise Science, 23, 600-615. https://doi.org/10.1123/pes.23.4.600

Lin, S., \& Yang, S. (2015). The Development of Fundamental Movement Skills by Children Aged Six to Nine. Universal Journal of Educational Research, 3(12), 1024-1027. https://doi.org/10.13189/ujer.2015.031211

Lopes, L., Santos, R., Pereira, B., \& Lopes, V. P. (2013). Associations between gross Motor Coordination and Academic Achievement in elementary school children. Human Movement Science, 32, 9-20. https://doi.org/10.1016/j.humov.2012.05.005

Lubans, D. R., Morgan, P. J., Cliff, D. P. Barnett, L. M., \& Okely, A. D. (2010). Fundamental Movement Skills in Children and Adolescents. Sports Med, 40, 1019. https://doi.org/10.2165/11536850-000000000-00000

Pagani, L. S., \& Messier, S. (2012). Links between motor skills and indicators of school readiness at kindergarten entry in urban disadvantaged children. Journal of Educational and Developmental Psychology, 2, 95-107. https://doi.org/10.5539/jedp.v2n1p95

Pitchford N. J., \& Outhwaite, L. A. (2016) Can Touch Screen Tablets be Used to Assess Cognitive and Motor Skills in Early Years Primary School Children? A Cross-Cultural Study. Front. Psychol. 7, 1666. https://doi.org/10.3389/fpsyg.2016.01666

Pitchford, N. J., Papini, C., Outhwaite, L. A., \& Gulliford, A. (2016). Fine Motor Skills Predict Maths Ability Better than They Predict Reading Ability in the Early Primary School Years. Front. Psychol. 7, 783. https://doi.org/10.3389/fpsyg.2016.00783

Roebers, C. M., Röthlisberger, M., Neuenschwander, R., Cimeli, P., Michel, E., \& Jäger, K. (2014). The relation between cognitive and motor performance and their relevance for children's transition to school: A latent variable approach. Human Movement Science, 33, 284-297. https://doi.org/10.1016/j.humov.2013.08.011

Sattelmair, J., \& Ratey, J. J. (2009). Physically active play and cognition: An academic matter. In Board of Trustees of the University of Illinois (Eds.), American Journal of Play (pp. 365-374). Champaign-Urbana, IL: University of Illinois.

Sgró, F., Schembri, R., Nicolosi, S., Manzo, G., \& Lipoma, M. (2013). A mixed-method approach for the assessment of fundamental movement skills in physical education. Procedia - Social and Behavioral Sciences, 106, 102-111. https://doi.org/10.1016/j.sbspro.2013.12.013

Skinner, R. A., \& Piek, J. P. (2001). Psychosocial implications of poor motor coordination in children and adolescents. Human Movement Science, 20, 73-94. https://doi.org/10.1016/S0167-9457(01)00029-X

Spessato, B. C., Gabbard, C., Valentini, N., \& Rudisill, M. (2013). Gender differences in Brazilian children's fundamental movement skill performance, Early Child Development and Care, 183(7), 916-923. https://doi.org/10.1080/03004430.2012.689761

Stöckel, T., \& Hughes, C. M. L. (2016). The relation between measures of cognitive and motor functioning in 5- to 
6-year-old children. Psychological Research, 80, 543-554. https://doi.org/10.1007/s00426-015-0662-0

Temple, V. A., Crane, J. R., Brown, A., Williams, B. L., \& Bell, R. I. (2016). Recreational activities and motor skills of children in kindergarten. Physical Education and Sport Pedagogy, 21(3), 268-280. https://doi.org/10.1080/17408989.2014.924494

Ulrich, D. A. (2000). The Test of Gross Motor Development. (2 ${ }^{\text {nd }}$ ed.) Austin, TX: PRO-ED. ISBN: 978-0761618201.

Westendorp, M., Hartman, E., Houwen, S., Smith, J., \& Visscher, C. (2011). The relationship between gross motor skills and academic achievement in children with learning disabilities. Research in Developmental Disabilities, 32(6), 2773-2779. https://doi.org/10.1016/j.ridd.2011.05.032

Wilson, A., Piek, J. P., \& Kane, R. (2013). The mediating role of social skills in the relationship between motor ability and internalizing symptoms in pre-primary children. Infant and Child Development, 22, 151-164. https://doi.org/10.1002/icd.1773

Wrotniak, B. H., Epstein, L. H., Dorn, J. M., Jones, K. E., \& Kondili, V. A. (2006). The Relationship Between Motor Proficiency and Physical Activity in Children. PEDIATRICS, 118(6). https://doi.org/10.1542/peds.2006-0742

\section{Copyrights}

Copyright for this article is retained by the author(s), with first publication rights granted to the journal.

This is an open-access article distributed under the terms and conditions of the Creative Commons Attribution license which permits unrestricted use, distribution, and reproduction in any medium, provided the original work is properly cited. 